\title{
Improvement of the Specificity of an Antiserum Raised against a Carrot Glycoprotein by Eliminating the Anti-glycan Antibody
}

\author{
Shinobu SATOH \\ Institute of Biological Sciences, University of Tsukuba, \\ Tsukuba, Ibaraki 305, Japan \\ Received June 7, 1990
}

\begin{abstract}
The high immunogenecity of xylose-containing glycans of plant glycoproteins caused a non-specific antiserum which reacted to numerous glycoproteins of carrot cells and bromelain on immunoblots. The antiserum raised against a carrot $M_{r}-57000$ glycoprotein was fractionated by affinity chromatography, using a column in which bromelain was coupled with $\mathrm{CNBr-Sepharose} \mathrm{4B}$. The passthrough and bound fractions contained anti-polypeptide moiety and anti-glycan moiety antibodies, respectively. The use of the pass-through fraction greatly improved the specificity when immunoblotting the total carrot proteins.
\end{abstract}

Even when a plant glycoprotein is highly purified and an antiserum is raised against it by using a healthy rabbit, numerous nonspecific bands sometimes appear in immunoblots when using the antiserum. This phenomenon is thought to be caused by the high immunogenecity of xylose molecules which is sometimes found only in glycans of plant glycoproteins. ${ }^{1)}$ Therefore, one should either raise a specific antiserum of rabbit by injecting chemically deglycosylated glycoproteins $^{11}$ or make monoclonal antibodies specifically against a polypeptide. ${ }^{2)}$ This report describes the reactivity of the antiserum raised against a non-deglycosylated carrot glycoprotein and the elimination of the anti-glycan antibody by simple affinity chromatography with a bromelain column to yield a specific antiserum.

\section{Materials and Methods}

Materials. A carrot $M_{r^{-}} 57,000$ glycoprotein (GP57) was purified by sequential column chromatography from the culture medium of carrot non-embryogenic callus as described previously. ${ }^{2}$

Bromelain (pineapple stem), ovalbumin (chicken egg), thyroglobulin (bovine), fetuin (fetal calf serum) and peroxidase (horseradish) were purchased from Sigma. Concanavalin $\mathrm{A}$ and soybean lectin were purchased from Seikagakukogyo, Tokyo.

Electrophoresis and Immunoblotting. Sodium dodecyl sulfate-polyacrylamide gel electrophoresis (SDS-PAGE) was performed as described previously ${ }^{2)}$ according to the method of Laemmli. ${ }^{3)}$ A Two-week-old liquid culture of non-embryogenic carrot callus was separated into cells and the culture medium by passing through a glass filter. The cells and $70 \%(\mathrm{v} / \mathrm{v})$ acetone precipitate of the culture medium were homogenized in an SDS-containing buffer for use with SDS-PAGE ${ }^{21}$ The proteins on the gels were stained with $0.25 \%$ Coomassie brilliant blue R-250 dissolved in $50 \%$ isopropanol and $10 \%$ acetic acid.

The proteins on the gel were then electrophoretically transfered to a nitrocellulose filter according to the method of Gershoni and Palade. ${ }^{4}$ The filter was first incubated in $2 \%$ bovine serum albumin dissolved in phosphate-buffered saline solution (PBS) composed of $10 \mathrm{~mm}$ sodium phosphate at $\mathrm{pH} 7.0$ and $150 \mathrm{~mm} \mathrm{NaCl}$ (BSA-PBS) for $1 \mathrm{hr}$, and then in $2 \%(\mathrm{v} / \mathrm{v})$ antiserum in BSA-PBS for $1 \mathrm{hr}$. After washing with $0.5 \%$ Triton $\mathrm{X}-100$ in PBS for $30 \mathrm{~min}$, the filter was incubated in $0.01 \%(\mathrm{v} / \mathrm{v})$ peroxidase conjugated goat anti-rabbit $\operatorname{IgG}(\mathrm{H}+\mathrm{L})$ (Jackson Immunoresearch Laboratories Inc., U.S.A.) in BSA-PBS for $1 \mathrm{hr}$, and then in PBS containing $0.03 \% 3,3$ -

Abbreviations: GP57, $M_{\mathrm{r}}-5,7000$ glycoprotein; PBS, phosphate-buffered saline solution; SDS-PAGE, sodium dodecyl sulfate-polyacrylamide gel electrophoresis; BSA-PBS, $2 \%$ bovine serum albumin dissolved in PBS. 
diaminobenzidine and $0.003 \% \quad \mathrm{H}_{2} \mathrm{O}_{2}$ for $3 \mathrm{~min}$, after washing with $0.5 \%$ Triton X-100 in PBS for $30 \mathrm{~min}$.

The proteins on the filter were stained with $0.1 \%$ Amide black $10 \mathrm{~B}$ dissolved in $45 \%$ methanol and $20 \%$ acetic acid.

Antiserum. The purified GP57 $(200 \mu \mathrm{g})$ was subjected to SDS-PAGE, and a band at GP57 was cut out after staining with Coomassie brilliant blue R-250. The gel strips were rinsed with PBS, crushed, dialysed against PBS overnight, emulsified with an equal volume of complete Freund's adjuvant (Nakarai, Japan), and then injected subcutaneously into a male rabbit (New Zealand White) every two weeks. Blood samples were taken at 2-week intervals, and the 5 th bleeding was used for further experiments.

Preparation of a Bromelain Column and Affinity Chromatography. Bromelain (pineapple stem, $200 \mathrm{mg}$ ) was dissolved in $20 \mathrm{ml}$ of coupling buffer $(0.1 \mathrm{M} \mathrm{Na}$-borate, $\mathrm{pH} 8.3,0.5 \mathrm{M} \mathrm{NaCl}$ ), and centrifuged at $12,000 \mathrm{rpm}$ for $10 \mathrm{~min}$. The supernatant was mixed for $2 \mathrm{hr}$ with $3 \mathrm{~g}$ of CNBr-Sepharose 4B (Pharmacia), which had been suspended in $1 \mathrm{~mm} \mathrm{HCl}$ and washed with the coupling buffer. After coupling, the gel was incubated in $1 \mathrm{M}$ ethanolamine at pH 8.0 for $2 \mathrm{hr}$, and then washed 4 times alternately with the coupling buffer and $0.1 \mathrm{M} \mathrm{Na}$-acetate at $\mathrm{pH} 4.0$ containing $0.5 \mathrm{M} \mathrm{NaCl}$. Then, the gel was incubated overnight in the coupling buffer containing $1 \mathrm{~mm}$ $p$-chloromercuric benzoate to inactivate the proteinase activity of bromelain and for preservation.

The bromelain column $(10 \mathrm{ml})$ was sequentially washed with $20 \mathrm{ml}$ of $0.1 \%$ Tween 20 in PBS, glycine- $\mathrm{HCl}$ at $\mathrm{pH} 2.8$, and then by PBS. The antiserum $(200 \mu 1)$ was then applied to the column, eluting with $20 \mathrm{ml}$ of PBS, and then washed with $20 \mathrm{ml}$ of $0.1 \%$ Tween 20 in PBS. The bound antibody was eluted by $20 \mathrm{ml}$ of glycine- $\mathrm{HCl}$ at $\mathrm{pH} 2.8$, and the $\mathrm{pH}$ of the eluates was immediately neutralized by adding $1 \mathrm{M}$ Tris- $\mathrm{HCl}$ at $\mathrm{pH} 8.0$. Each $0.5 \mathrm{ml}$ fraction was collected and the absorbance at $280 \mathrm{~nm}$ was measured. The fractions containing proteins were added to 50 volumes of BSA-PBS and used for immunoblotting.

Deglycosylation. Deglycosylation of GP57 was performed chemically by using trifluoromethanesulfonic acid as described previously ${ }^{2)}$ according to the method of Edge et al. ${ }^{5}$

\section{Results and Discussion}

When the antiserum raised against GP57 was used for immunoblotting the total medium proteins or cell proteins of cultured carrot cells, numerous non-specific bands appeared in both cases (Fig. 1), whereas the monoclonal antibody raised against the polypeptide of
GP57 showed only a major GP57 band in the medium proteins and a minor band in the cell proteins. ${ }^{2)}$ It was not possible to improve the blots, even when harder washing conditions such as the addition of SDS were used.

Because GP57 is known to have glycans containing xylose molecules, ${ }^{2)}$ the immunoreactivity of the serum against various authentic glycoproteins (ovalbumin, thyroglobulin, horseradish peroxidase, soybean lectin and bromelain) and a lectin without glycans (concanavalin A). Among them, only bromelain was known to have xylose-containing glycans. ${ }^{6)}$ As shown in Fig. 2b, a strong reaction was observed only in horseradish peroxidase and bromelain (lanes 4 and 6), both of which were purified from plant materials. However, in the blot of peroxidase, the antibody reacted not to a major component but to minor contamination (Figs. $2 a$ and $b$ ). Therefore, bromelain was used for the affinity column preparation and fractionation of the antiserum.

Figure 3 shows the immunoblotting of intact or deglycosylated GP57, using the antiserum fractions obtained from the bromelain column.

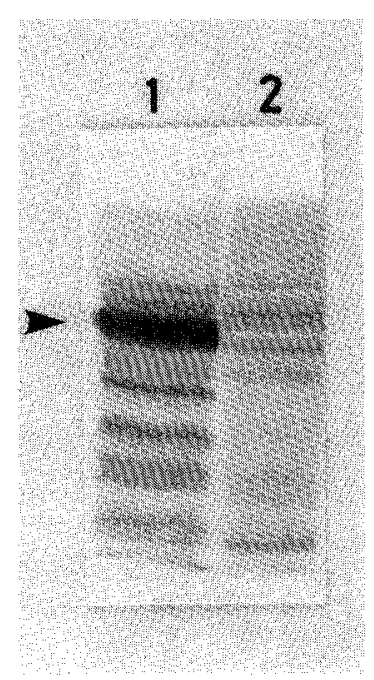

Fig. 1. Immunoblotting of Carrot Proteins.

Total medium proteins (lane 1) and cell proteins (lane 2) of cultured carrot callus were subjected to SDS-PAGE and immunoblotting, using the antiserum raised against GP57. The arrow indicates the position of GP57. 


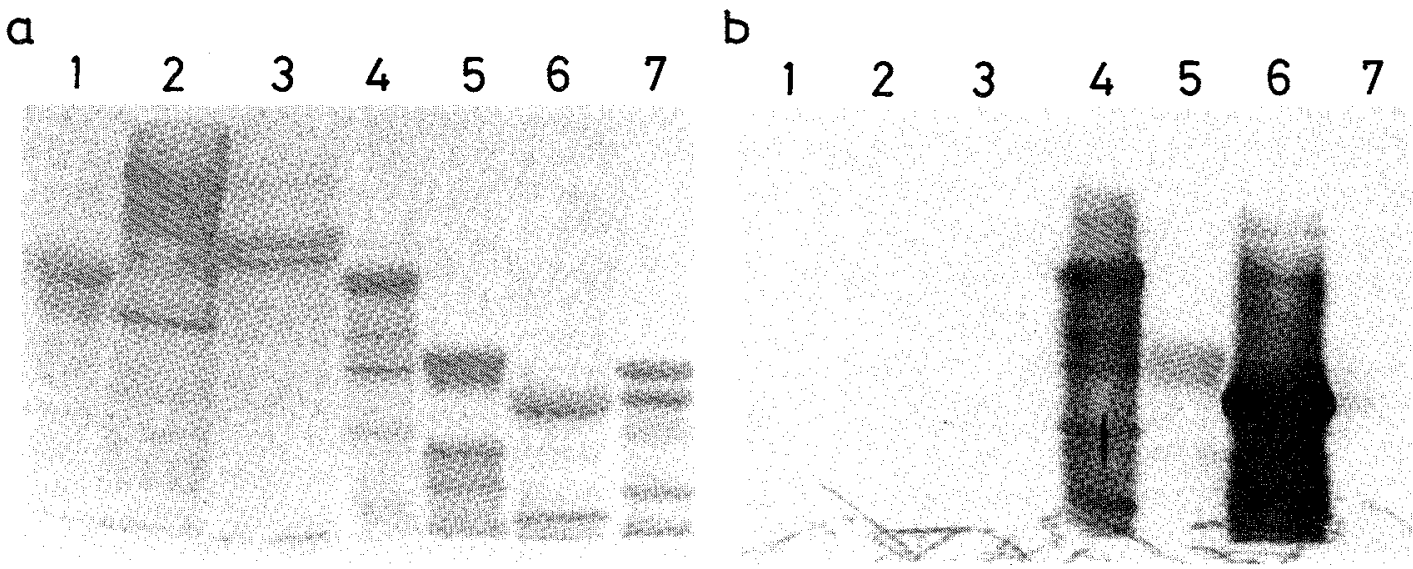

Fig. 2. Immunoreactivity of the Antiserum against Authentic Proteins.

Ten micrograms each of ovalbumin (lane 1), thyroglobulin (lane 2), fetuin (lane 3), peroxidase (lane 4), soybean lectin (lane 5), bromelain (lane 6) and concanavalin A (lane 7) were subjected to SDS-PAGE, transferred to a nitrocellulose filter and then stained by Amide black 10 b (a) or immunologically detected by the antiserum raised against GP57 (b).

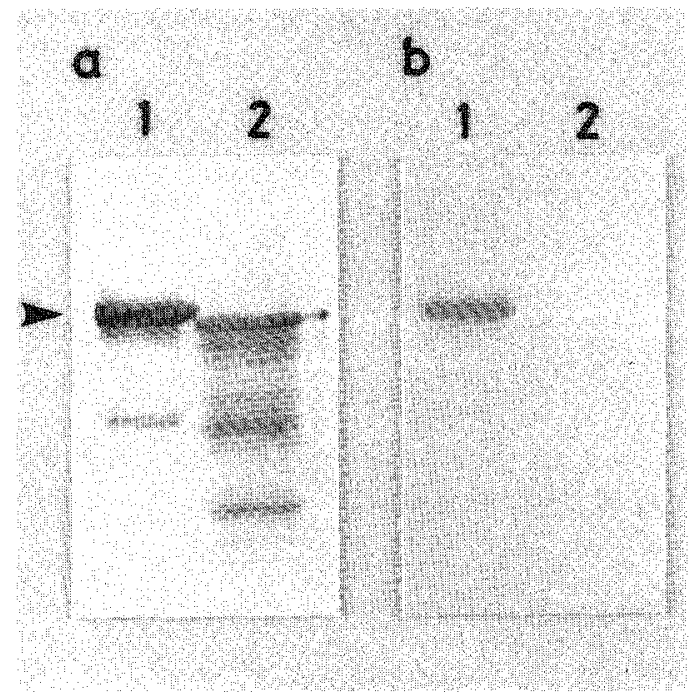

Fig. 3. Immunoreactivity of the Fractionated Antiserum against GP57.

Two micrograms each of intact (lane 1) and chemically deglycosylated (lane 2) GP57 were subjected to SDS-PAGE and immunoblotting, using the pass-through (a) and bound (b) fractions of the antiserum separated by a bromelain column. The arrow indicates the position of GP57.

The pass-through fraction reacted to both intact and deglycosylated GP57, whereas the bound fraction eluted with glycine- $\mathrm{HCl}$ at $\mathrm{pH}$ 2.8 reacted to only intact GP57. This means that the pass-through and bound fractions

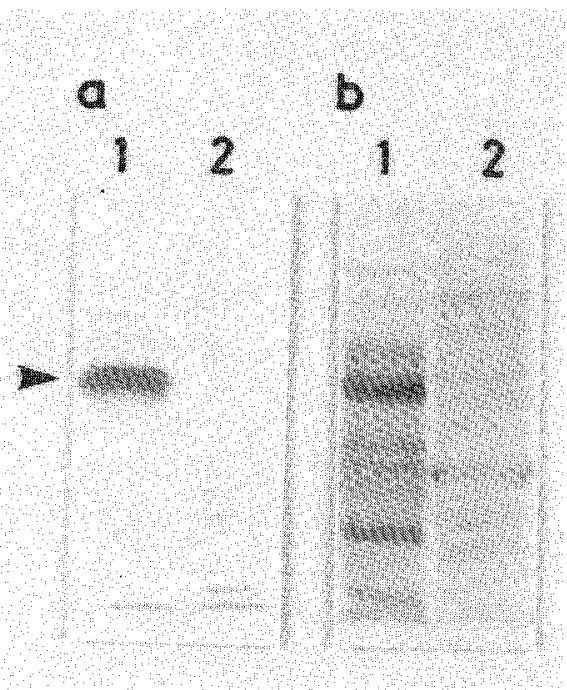

Fig. 4. Comparison of the Immunoblots of Carrot Proteins between Fractions of the Antiserum.

Total medium proteins (lane 1) and cell proteins (lane 2) of cultured carrot callus were subjected to SDS-PAGE and immunoblotting, using the pass-through (a) and bound (b) fractions of the antiserum separated by a bromelain column. The arrow indicates the position of GP57.

contained anti-polypeptide and anti-glycan antibodies, respectively.

The fractionated antibody was also used for the immunoblotting of the total medium and cell proteins of carrot. As shown in Fig. 4a, 
almost all the non-specific bands disappeared when the pass-through fraction was used. The non-specific band could be decreased more efficiently when the pass-through fraction was re-applied to the column. Similar results were obtained when the serum was incubated in $1 \%$ $p$-chloromercuric benzoate-treated bromelain overnight, although the background of the blot was increased. However, the addition of xylose to the serum showed no effects on the blot.

Complex asparagine-linked oligosaccharides containing $\beta, 1 \rightarrow 2$ linked xylose residues have been found in many plant glycoproteins, ${ }^{7-9)}$ and may be highly immunogenic. The presence of xylose-containing glycans in the immunogens as either part of the glycoproteins or as contamination should cause a non-specific antiserum. However, the anti-glycan antibody can be eliminated by simple affinity chromatography using a bromelain column as shown in this report.

\section{References}

1) M. Laurière, C. Laurière, M. J. Chrispeels, K. D. Johnson and A. Sturm, Plant Physiol., 90, 1182 (1989).

2) S. Satoh and T. Fujii, Planta, 175, 364 (1988).

3) U. K. Laemmli, Nature, 227, 680 (1970).

4) J. M. Gershoni and G. E. Palade, Anal. Biochem., 124, 396 (1982)

5) A. S. B. Edge, C. R. Faltynek, L. Hof, L. E. Reichert and P. Weber, Anal. Biochem., 118, 131 (1981).

6) N. Takahashi, T. Hotta, H. Ishihara, M. Mori, S. Tejima, R. Bligny, T. Akazawa, S. Endo and Y. Arata, Biochemistry, 25, 388 (1986).

7) D. Astrford, R. A. Dwek, J. K. Welply, S. Amatayakul, S. W. Homans, H. Lis, G. N. Taylor, N. Sharon and T. W. Rademacher, Eur. J. Biochem., 166, 311 (1987).

8) B. Fournet, Y. Leroy, J-M. Wieruszeski, J. Montreuil, R. D. Poretz and R. Goldberg, Eur. J. Biochem., 166, 321 (1987).

9) A. Sturm, J. A. Van Kuik, J. F. G. Vliegenthart and M. J. Chrispeels, J. Biol. Chem., 262, 13392 (1987). 